\title{
New generation of resilient wheels bonatrans for tram cars
}

\begin{abstract}
This papers deals with the new design of resilient wheels with high radial elasticity comparing another designs. The aim of this new wheel design is to increase passenger comfort and noise reduction during service of tram cars in cities. Tyre of the wheel is designed also as brake disc. In this paper will be describe also results of laboratory test of the wheel stiffness and comparison with previous wheel generation including other wheel parameters. Because primary role of the wheel is done by rubber segments also its results will be described.
\end{abstract}

\section{Introduction}

Increasing transport congestion in urban areas due to excessive motor vehicle traffic can favour the development of passenger rail transport. Modern passenger rail transport systems with separated trackways work by optimized schedules thereby minimizing random overload of the communication network. The passenger railway transport in the urban areas includes traditional trams (high floor), modern trams (low floor), fast trams, rail and subway cars. The next few years are likely to see action taken to stimulate the development or tram vehicles by improving its profitability, which can be obtained through better ergonomics, higher level of safety and less harmful impact on the environment [6].

Studies and comparative analysis [3,4] showed that the same noise level generated by the rail transport system is less irritating to the audience than road traffic noise. Also the noise of trams is less acute in comparison with the noise emitted by buses [5]. In the process of movement during modes of rail transport, a person is exposed to series of interactions, which to some extend determine their psycho-physiological state. This will influence the choice of means of transport used in the future, provided there is an alternative [7]. An analysis of literature shows that the effects on the body of two or more arduous factors such as noise and vibration, the combined adverse effects will be grater, compared to the situation if each occurred separately among others $[1,2]$.

The new design of Bonatrans tram wheel has been developed for new concepts of tram cars, distinguished by a very low level of vibrations during their run and a low level of emitted noise. At the same time the new wheel provides for a high passenger comfort. All these aspects, in addition to other vehicle parts, are affected just by the wheel itself, which at present serves as a brake disc, too. It is a wheel with a high radial compliance, sprung up by rubber segments. As the wheels are used in low-floor trams, which provide another benefit for passengers when boarding and exiting, the wheel is designed to be mounted on the axle support via bearings. One of such trams is a product made by ŠKODA TRANSPORTATION a.s., Plzeň, Czech Republic see Figure 1.

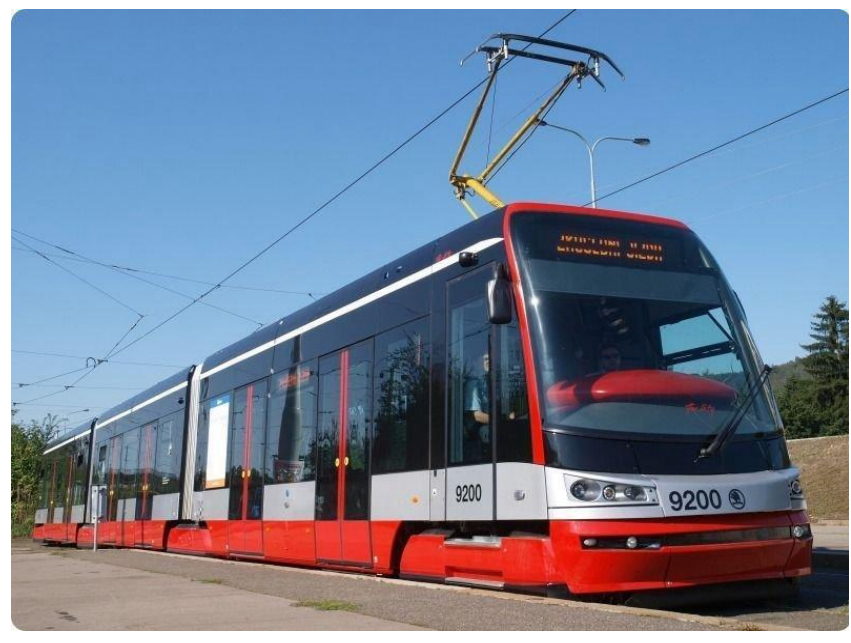

Figure 1- Low floor tram car 15T made by ŠKODA TRANSPORTATION a.s.

\subsection{Resilient wheel characteristics}

The wheel deformation characteristics are given by the design of metallic parts and used rubber elements. The rubber elements are the most significant part of the wheel. In addition to their shape and way of loading during operation, the applied rubber material is important, as well. Compared with the previous 
generation of BONATRANS tram wheels with Vshaped rubber segments, the new wheel design is approximately three times more elastic.
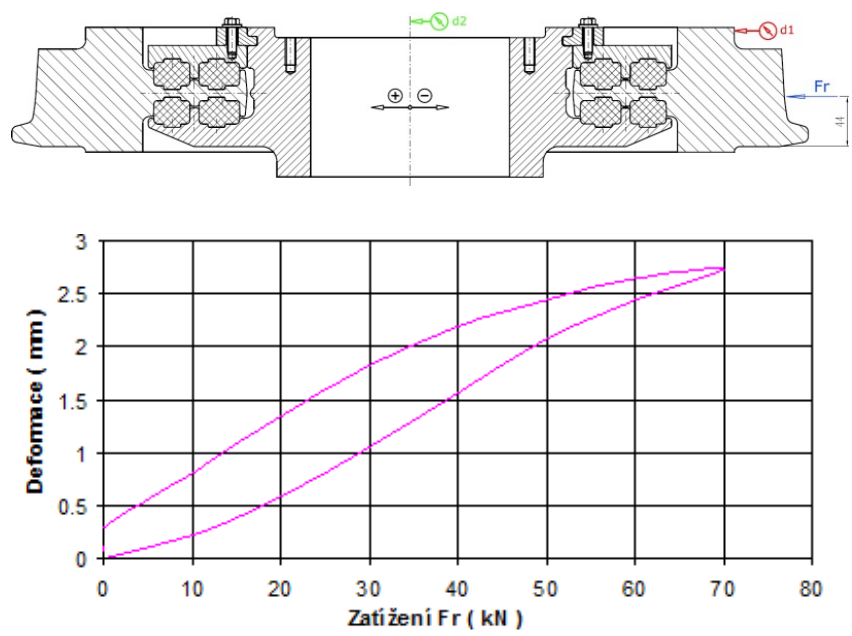

Figure 2- Schema of the new resilient tram wheel and wheel deformation (axis Y) towards radial load (axis X).

Figure 2 shows the wheel deformation characteristics at the vertical wheel load. The wheel deformation characteristics can be further tuned up and changed within a range of approx. $+-20 \%$ by changing the rubber pre-stress, shape and dimensions of rubber segments, as well as the rubber material. Change of the rubber segment material is always the most demanding task in respect of the dynamic loading during operation and the requirements for a sufficient service life of these segments.

\section{Wheel construction}

\subsection{Dimensions and shapes of rubber segments}

Basic dimensions of rubber segments and their shapes are based on the build-up options given by the wheel design and the type of tram vehicle, in which they are to be used. Following their first proposal made by the designer a lot of analyses of the segment loading take place by means of the FEM numerical simulation (Finite Element Method). This long and time-consuming stage is aimed at the optimization of the segment shape and size in order to eliminate areas with dangerous stress signalling possible damage of the rubber segment. Figure 3 shows the stress condition of a rubber segment applied in the new wheel design.

\subsection{Material of rubber segments}

The original rubber material for the former tram wheel generation designed with V-shaped rubber segments could not be used as these segments are pre-stressed after their assembly in wheels and loaded in radial direction by the deformation amplitude of +$0.7 \mathrm{~mm}$ in consequence of wheel rotation. The loading amplitude in real operation may be lower due to actual tram occupancy by passengers which does not always reach maximum capacity; nevertheless, it always simulates the maximum values during testing. In the new wheel design the rubber segments are prestressed and loaded in radial direction with the amplitude of +-3 $\mathrm{mm}$. When compared with V-shaped rubber segments in the case of which the deformation
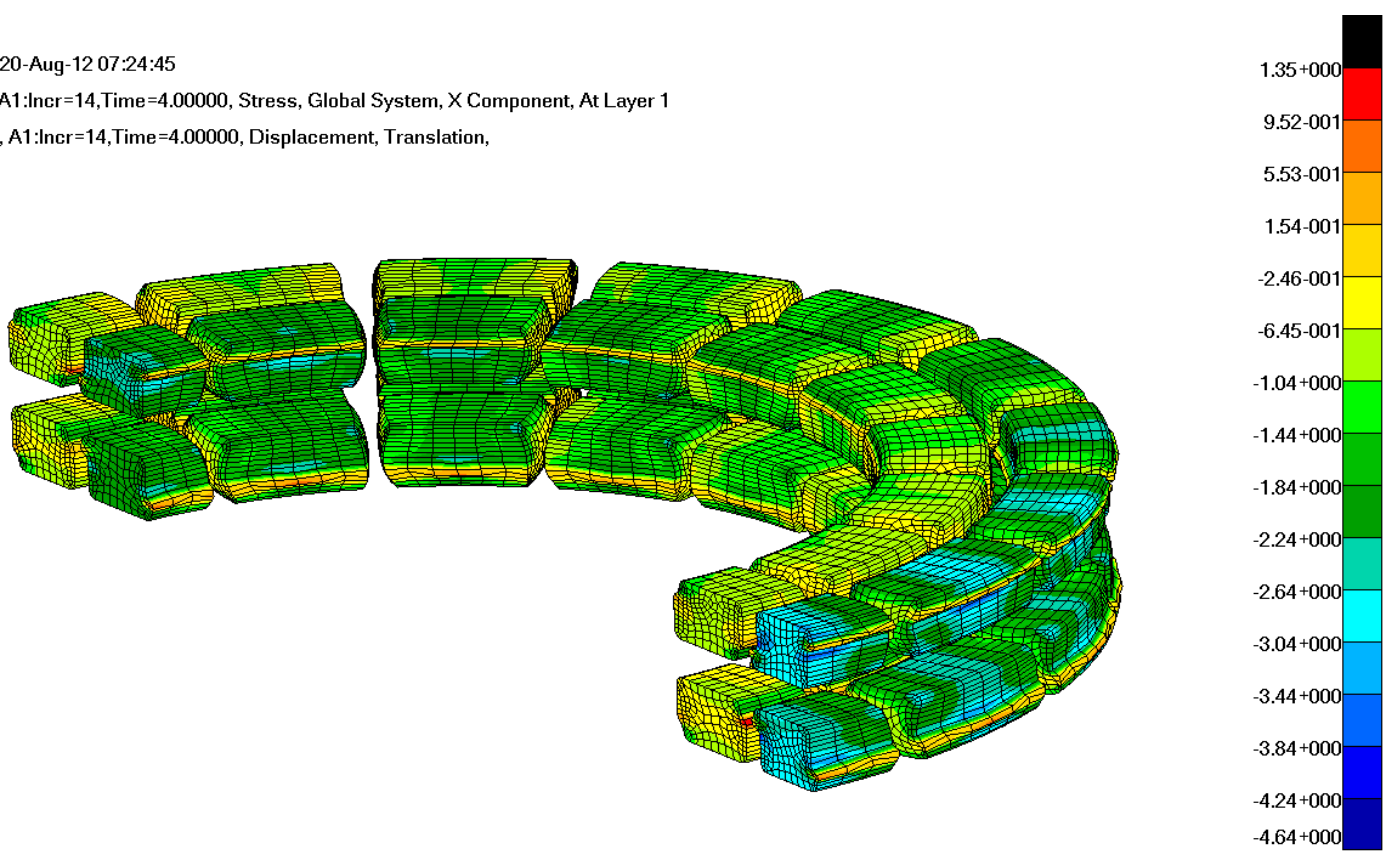
in compression prevails, the new segments are, above all, shear deformed by operational loading. In view of all that new rubber mixtures had to be developed, further tested and evaluated for future service. They are in most cases mixtures on the styrene-butylene (SBR) basis or natural rubber (NR) basis. Figure 4 shows a picture of rubber segment in the new wheel constructions and old one with $\mathrm{V}$ shape.

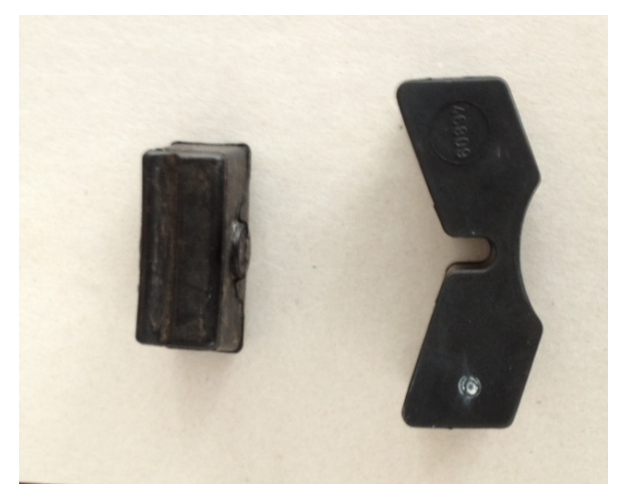

Figure 4. Rubber segment for new and old resilient wheel design BONATRANS.

\section{Rubber wheel testing}

\subsection{Tests of rubber segments}

To verify the stiffness and fatigue conditions of the proposed shapes of rubber segments and their materials, a jig shown in Figure 5 has been designed. This jig simulates the exact mounting and/or prestressing of rubber segments in wheel and their load in vertical direction. The fixture is adjusted for mounting in an electro-hydraulic test equipment, where besides the measurement of static and dynamic wheel stiffness a long-term run of the wheel with radial load from the vehicle and passenger weights is simulated.

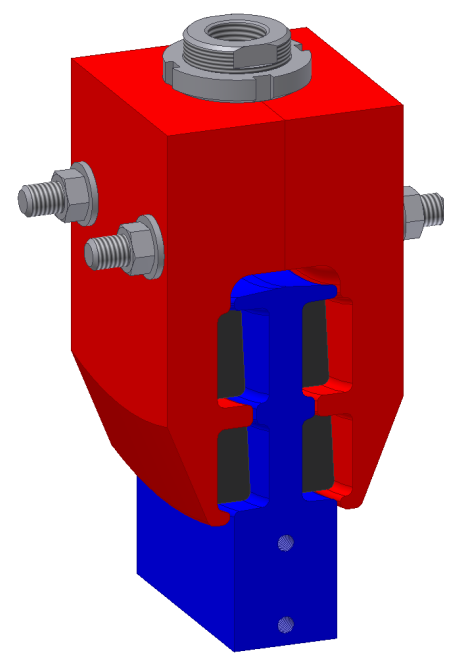

Figure 5 Schema of jig for testing of rubber segments

\subsection{Test of static stiffness of rubber segments}

The test of the rubber segment static stiffness was performed by first applying three pre-cycles with a speed of loading of $30 \mathrm{~mm}$ per minute with deformations from $-3 \mathrm{~mm}$ to $+3 \mathrm{~mm}$. The plotting of hysteresis curve then proceeded within the same range of deformations of $+-3 \mathrm{~mm}$ at a speed of loading of 10 $\mathrm{mm}$ per minute. Typical progress of the hysteresis curve is shown in Figures 6 and 7. In addition to measuring deformation characteristics at a room temperature of $20^{\circ} \mathrm{C}$, the measurement was also conducted at an increased temperature of $+40^{\circ} \mathrm{C}$ and at reduced temperatures of $0^{\circ} \mathrm{C},-20^{\circ} \mathrm{C},-40^{\circ} \mathrm{C},-70^{\circ} \mathrm{C}$. As seen on the pictures of rubber static deformation, the SBR-based mixture is approx. four times stiffer at a loading temperature of $-40^{\circ} \mathrm{C}$ in comparison with the NR-based mixture in which stiffness is increased at a temperature of $-40^{\circ} \mathrm{C}$ by approx. 1.8 times against the values at a room temperature of $20^{\circ} \mathrm{C}$.

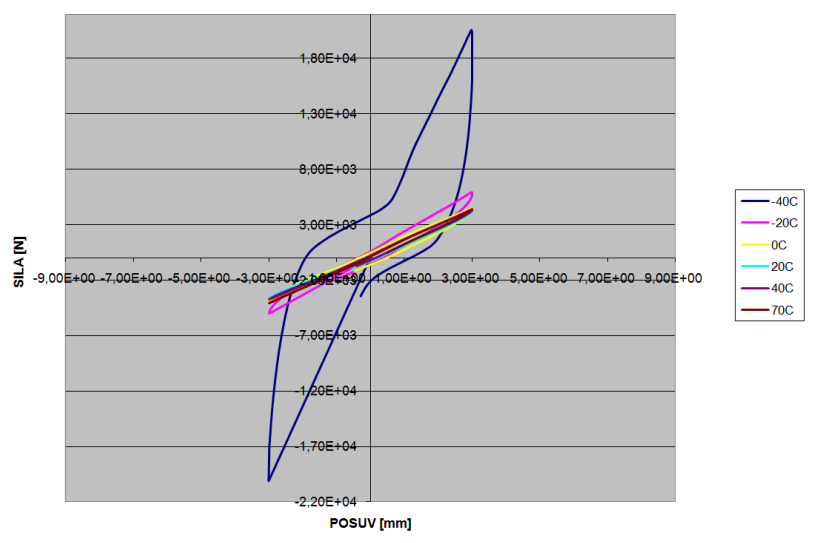

Figure 6- Graph of hysteresis curve during rubber loading $10 \mathrm{~mm} / \mathrm{min}$. for $\mathrm{SBR}$ rubber (axis Y radial load, axis X deformation)

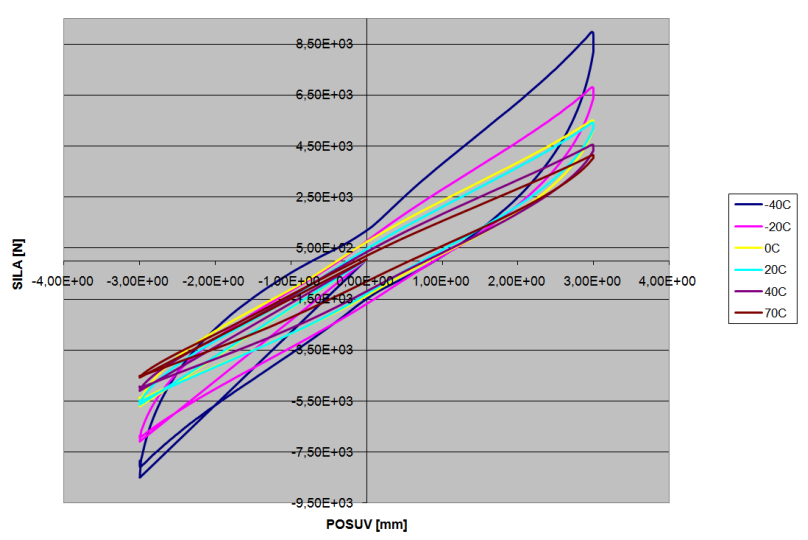

Figure 7- Graph of hysteresis curve during rubber loading $10 \mathrm{~mm} / \mathrm{min}$. for NR rubber (axis Y radial load, axis X deformation)

\subsection{Fatigue test of rubber segments}

The fatigue test of rubber segments serves to estimate the degradation and service life of segments in real operation. Testing at BONATRANS is subject to the following conditions:

- loading frequency: $9.5 \mathrm{~Hz}$;

- deformation amplitude: $+-3 \mathrm{~mm}$; and

- 26 million cycles, which in case of wheel dia. $650 \mathrm{~mm}$ represents a travel of approx. $53,000 \mathrm{~km}$.

The above service life test means a continuous operation of the test equipment at a length of 32 days. The following parameters are evaluated during the test and at its end:

- degradation speed of rubber element and/or the speed of growth of permanent deformation; 
- permanent deformation of rubber segment shortly after finishing the test;

- regeneration ability of the rubber segment - change of the permanent deformation of an unloaded segment after 24 hours following the end of test; and - damage to the rubber segment (cracks, flaking and chipping, bruises)

Within the framework of all tests, the value of permanent deformation is considered the most important test from the viewpoint of service reliability and safety. Its maximum and/or limiting value is specified by the wheel manufacturer and is determined so that the wheel is capable of meeting its function and transmitting the forces from operation, especially the torques upon the vehicle starting and braking when the wheel tyre does not slip in relation to the wheel disc. Figures 8 representing SBR- and NR-based rubber elements after the fatigue tests show that the SBR-based rubber mixture was considerably damaged and distinguished by permanent deformations exceeding $15 \%$ so that this mixture, which is satisfactory with standard designs of rubber-suspended wheels, cannot be used for the high elasticity resilient rubber wheels. The new design of tram car wheel with high radial deformations in service above $1.5 \mathrm{~mm}$ requires the use of NR type mixture.

\subsection{Fatigue test of complete wheels}

Existing fatigue tests of wheels conducted on a hydraulic or resonance test equipment made it possible to load the wheel cyclically only by radial force or a combination of radial and lateral forces. This way is, however, insufficient for highly resilient, rubber-suspended wheels, as it does not take into consideration the tangential load upon the cars starting and braking. That is why BONATRANS decided on a construction of the electro-hydraulic test equipment referred to in Figure 9. This equipment enables to load the wheel by means of a rotating rail in the same way as in real operation. The wheel tyre service life can be concurrently simulated too, as well as its wear and tear in the wheel - rail contact. In addition to the degradation of rubber elements, we shall also be able to evaluate the change of the wheel stiffness with the rotation frequency and/or the speed of the wheel run. Once again the test will be demanding both from the viewpoint of time and energy consumed.

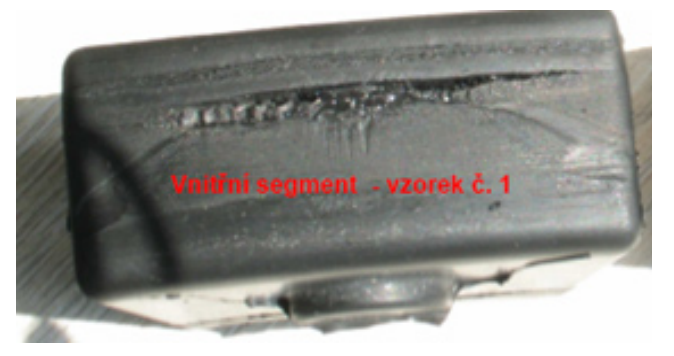

Figure 8- Picture of rubber segment after fatigue test - left SBR mixture, right NR mixture

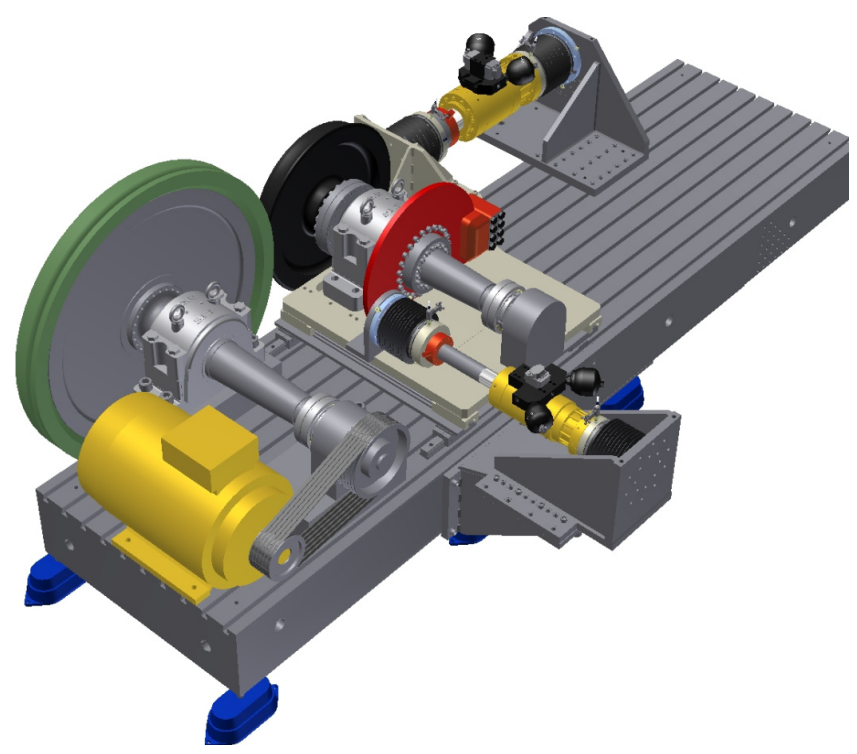

Figure 9- Schema of new testing equipment for resilient wheel

\section{Strength verification of metallic parts of sus- pended wheel \\ 4.1 Wheel computation}

The wheel stress and deformation conditions were analysed by a combination of three methods of loading, taking place in operation: they are the vertical load upon running on a straight track; radial and lateral loading upon the vehicle running along a curve; and radial and lateral wheel loading upon running over a crossing and across the switches/points. The wheel model considers the real shape of separate parts, including the pre-stressing of rubber elements during their assembly in the wheel. The wheel network for a model required for computation applying the Finite Element Method (FEM) has been created by SOLID type elements. The wheel model has 215,000 elements, with a total number of approx. 270,000 nodes.

\subsection{Results of wheel strength analysis}

Analysis of the tensioning conditions in metallic parts is performed according to the Crossland Criterion for material multiple-axis fatigue. The highest stresses are found in the tyre if in the condition worn to the service limit. The maximum of a double value of the effective amplitude according to the Crossland theory is $209 \mathrm{MPa}$. Safety in relation to the allowed stress of the material used is in this case equal to

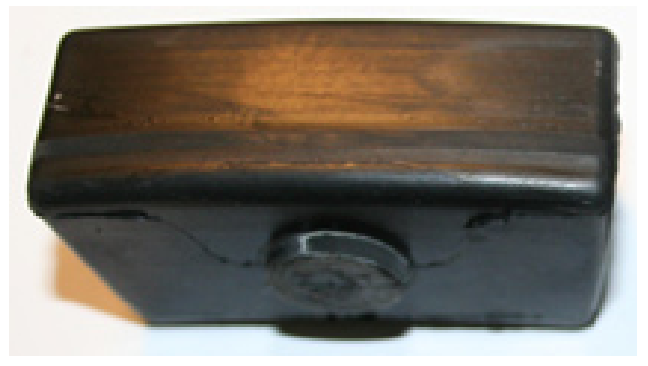

POJAZDY SZYNOWE NR 2/2013 


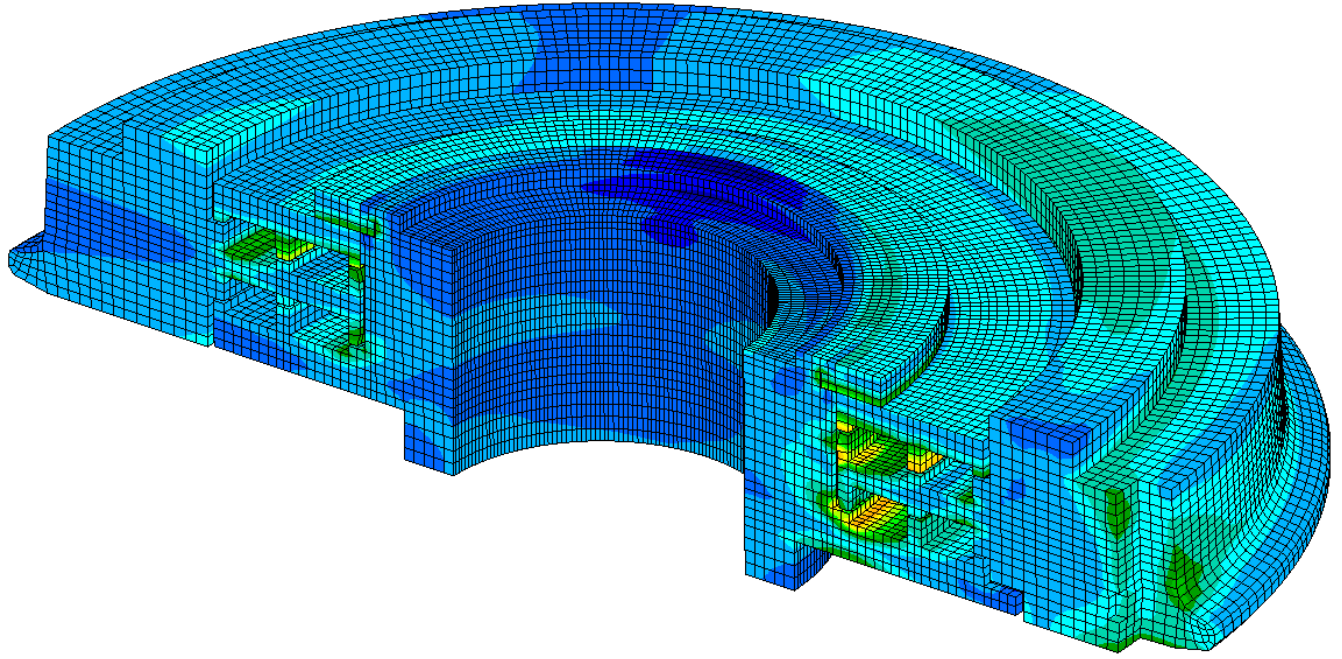

Figure 10- FEA wheel model and double value of the effective amplitude stress according to Crossland theory

1.72. Verification of accuracy of the wheel mathematical model behaviour was accomplished by comparing the deformations of separate wheel parts at the defined loads, taking place on BONATRANS test stand. Figure 10 shows the wheel model and its stresses upon the radial and lateral loading.

\section{Conclusion}

Rubber wheels with a high radial elasticity designed by BONATRANS represent a new generation of wheels for trams and are distinguished for a low noise level, as well as excellent deformation characteristics in radial and lateral directions, increasing the passenger comfort during the vehicle run. In addition to these positive features, they result in increased demands put on the material of rubber segments and wheel metallic parts with regard to higher loads or deformations of these parts. An important aspect in the development of such wheel design are also the test procedures proposed to verify to the maximum possible extent the wheel behaviour and the service life of the wheel separate parts, especially the rubber parts, prior to commissioning and establishing the wheels in real operation.

\section{References}

[1] Engel Z.: Ochrona środowiska przed drganiami $i$ hałasem PWN, Warszawa 2001

[2] Koton J., Majewski A.: Drgania $i$ hatas na stanowiskach pracy $w$ środkach komunkacji miejskiej - badania dozymetryczne. Bezpieczeństwo pracy 2004.

[3] Tomaszewski F., Orczyk M.: Ocena poziomu hałasu wewnatrz tramwajów na podstawie badań. Pojazdy Szynowe 2007, 4.

[4] Uhl T.: Prace badawcze Katedry Robotyki i Dynamiki Maszyn. Monografie WIMiR. Problemy Inżynierii Mechanicznej i Robotyki Kraków 2002

[5] Uhl T., Batko W., Skorupa M., Korbiel T.: Diagnostyczne badania stanu technicznego pojazdów tramwajowych w MPK Kraków S.A., AGH Kraków 2002.

[6] Zajac G.: Studies of vibroacustic effects in trams. Problems of maintenance of sustainable technological systrmems. PNTTE, Warszawa 2010.

[7] Zajac G.: Badania hałasu $i$ drgań $w$ tramwajach. Technika Transportu Szynowego nr 9/2011 r. 